\title{
EFFECT OF ACCESS TO AGRICULTURE CREDIT ON FARM INCOME IN THE TALENSI DISTRICT OF NORTHERN GHANA
}

\author{
Ehiakpor Dennis Sedem, Adzawla William, Danso-Abbeam Gideon \\ Department of Agricultural and Resource Economics, University for Development Studies, \\ Tamale, Ghana \\ E-mail: kdennisgh@yahoo.com, adzawlawilliam@yahoo.com, \\ nanayawdansoabbeam@gmail.com
}

\begin{abstract}
Agricultural credit is a vital service for agricultural growth and development. Against this milieu, this study examined the effect of this variable on farm income in the Talensi District of the Upper East region of Ghana. Through a two-stage sampling approach, 168 crop farmers were randomly selected. Heckman two-stage treatment effect model was estimated to correct for selectivity biases. Empirical results from the study indicated that the probability of accessing credit was higher for highly educated farmers, farmers belonging to a farmer group, farmers with large farm size, farmers who had access to extension service, female farmers and the elderly. Further, access to credit had a positive significant effect on farm income. Therefore, the study concluded that improving access to agricultural credit service could be a potential source of poverty reduction among farmers in the district. To enhance farmers' access to agricultural credit, intensification of farmer-based-organization is highly recommended. Farm-level policies oriented towards farmer's access to financial credit should also be encouraged.
\end{abstract}

\section{KEY WORDS}

Credit, extension service, farm income, Ghana, treatment effect model.

Over the years (2005/06 - 2012/13), the poverty level of Ghana has declined by $7.7 \%$. Nevertheless, Ghana Statistical Service survey in 2012/2013 suggests that about a quarter of Ghanaians are poor whilst under a tenth of the population are still trapped in extreme poverty (Ghana Statistical Service [GSS], 2014). The report further revealed that the rural population contributed about $78 \%$ to the total poverty of the country. This is mostly concentrated in rural savannah where this present study is located (GSS, 2014). Unfortunately, agriculture has over the years remained the major source of livelihood for these households.

In Ghana, the agricultural sector is a major backbone of the economy and a major source of foreign exchange. The sector employs about $42 \%$ of Ghana's workforce and with little non-farm diversification options. From GSS (2012), about $90 \%$ of the farmers produce less than 2 hectares of farm lands, using traditional methods, inputs and tools. This is largely due to market conditions such as lack of credit which constraint farmers from investing into their activities. As pointed out by Food and Agriculture Organization [FAO] (2015), lack of market is the major limiting factor to the growth of the agricultural sector and rural development at large. With recent threats of climate change and the rapid advancement of technology, more capital investment in agriculture and human capacity development are required by the farmers to at least continue to make their living out of farming. As a result, the Government of Ghana has continually made considerable budgetary allocations to improving the sector. Other stakeholders in the agricultural sector such as international and local funding agencies, non-governmental organizations and financial institutions have and continue to make investments in the agricultural sector in terms of credit (both cash and kind). For example, Association of Church-based Development Project (ACDEP) in Northern Ghana through Northern Rural Growth Programme (NRGP) do not only offer extension services to farmers but link farmers to financial institutions for credit. Given the scale of investment from both government and other stakeholders, the value for money in terms of 
increase in farm output is an important policy question. This calls for appropriate empirical evidence addressing the effects of this public investment on farm output. The objective of this paper is to quantify the effects of access to agricultural credit on farm income.

Credit and its Role in Agriculture. Generally, agriculture credit refers to the productive resources provided to farmers without immediate payment receipts but with an agreement on future repayments, mostly, after the production season. By this definition, agricultural credit does not only take cash forms but also, in the form of 'input-supply'. Under resource-poor farming conditions and large scale farming, credit is an important component since it formed a major source of transformation and modernization of the agricultural sector. Unarguably, most of the recent technologies with high potential of bringing about the modernization of the agriculture sector require high capital investment, which subsistence farmers are unable to provide. As a mitigation strategy, most of the farmers continue to produce crops and varieties that require less capital investment and using traditional production systems. Generally, credit allocation to agriculture is low and as such, remained a major challenge to agricultural investment (FAO, 2015). As a result, Meyer (2007) argued that microfinance services should be integrated into crop production since it has the potential of increasing crop production and improving the lives of farmers. In the Upper East region of Ghana, for instance, Quaye (2008) reported that only $19 \%$ of the households have access to credit. Nonetheless, various empirical studies such as Asres et al., (2014) have estimated that credit has a positive effect in reducing inefficiencies through the alleviation of capital constraint and enables farmers to procure inputs on time.

\section{METHODOLOGY OF RESEARCH}

Study location. The study is conducted in the Talensi district of the Upper East region of the Republic of Ghana. The district is one of the thirteen districts of the region. Its capital is Tongo. The district has a total population of about 40,363 as at the 2010 National Housing and Population Census. The lands are generally undulating, making it suitable for agricultural purposes. However due to its location, the district experiences a unimodal rainfall with torrential and poorly districted rains. The duration of the rain is short (May-September) relative to the dry season (October- April). Agriculture is the major employer of the citizens in the district and hence relies heavily on farm income as a major source of livelihood. Crops commonly grown in the district include maize, millet, rice, groundnut, sorghum and yam.

Sampling and Data Collection Procedure. In empirical studies, sampling is essential and the method adopted in the selection process must justify the nature of the population examined. In this study for instance, a majority of the economically active population in the district are involved in agriculture. This means that collecting a census data would require high finance, time, personnel and other resources. Therefore, considering these limitations, the study adopted a sample through sampling. The study through a two-stage sampling selected 168 crop farmers as the study sample. In the first stage, the study purposively selected Talensi district and crop farmers from the district. Secondly, the study selected six communities using simple random and also, using simple random sampling approach, 28 crop farmers from each community were selected. The use of simple random in the selection of the final respondents means that the study is able to make statistical inferences and generalizations. The questionnaire was designed and used for the data collection.

Estimation approach. The study estimated a treatment effect model to measure the effect of agricultural credit on crop income and to correct the problem with self-section or selection bias in the data set. This is because farmers in the study who had access to agricultural credit may have unobserved characteristics such as production skills and selfmotivation that may improve their probability to participate as well as their production or income. Thus, selection bias may arise simply because those who had access to credit and their counterparts may differ for reasons other than the fact that the former had access to credit. In principle, the treatment effect model is one of the extensions of the Heckman's twostage model. One of the major observable differences between the treatment effect model and the Heckman selection model is that the dependent variable in the selection equation 
becomes an independent variable in the outcome equation of the former model but not in the latter model. Like Heckman's model (Heckman, 1979), the treatment effect model has two equations: the selection equation and the substantive (outcome) equation. For instance, in this study, the objective is to examine the effect of credit constraint on farm income; therefore, a credit function is the selection equation and a farm income function is a substantive equation. The selection equation is a binary response model, usually, a probit model while the second, a linear (average response) model. In the estimation process, the selection equation is first estimated and the predicted values of the dependent variable (in this case, access to credit) obtained and used to construct an additional variable, known as an Inverse Mills Ratio (IMR). The IMR is used as an additional variable in the substantive equation to correct sample selection and frees the independent variables from any bias, hence, measure the true effect of the selection variable on the outcome variable. Generally, given a crop income function as:

$$
Y_{i}=\delta A_{i}+\beta_{i} x_{i}+v_{i} \quad i=1,2,3 \ldots . n
$$

Where $Y_{i}$ is crop income, $A_{i}$ is the selection variable (in this case, access to credit) and $X_{i}$ are a set of exogenous variables. Also, given that $A_{i}$ is influenced by a set of exogenous variables $\left(Z_{i}\right)$, then, we have:

$$
A_{i}^{*}=\omega Z_{i}^{1}+u_{i}
$$

Where $A_{i}^{*}$ is the latent variable (since $A_{i}$ is unobserved) that is defined as:

$$
A_{i}=1 \text { if } A_{i}^{*}>0, \text { otherwise } A_{i}=0
$$

Since we indicated that inert characteristics may also influence $A_{i}$, it implied that $v_{i}$ and $u_{i}$ may be correlated, hence, ordinary least square estimation of the outcome equation may not yield consistent parameters (Greene, 2008). Therefore, the expected outcome is given as:

$$
E /\left(A_{i}, x_{i}, Z_{i}\right)=x_{i}^{\prime} \beta+\delta A_{i}+E\left(v_{i} / A_{i}, x_{i}, Z_{i}\right)
$$

Through extrapolation of $E\left(v_{i} / A_{i}, x_{i}, Z_{i}\right)$, IMR is generated as:

$$
\lambda_{i}=\frac{\phi\left(-z_{i} \gamma\right)}{1-\Phi\left(-z_{i} \gamma\right)}
$$

Where $\phi\left(-z_{i} \gamma\right)$ is the probability density function and $\Phi\left(-z_{i} \gamma\right)$ is the cumulative probability function. The IMR describes the ratio of the ordinate of a standard normal to the tail area of the distribution and provides OLS selection corrected estimates (Greene, 2003). If the IMR is statistically significant, then a significant difference exist between farmers with access to credit and farmers without access to credit and therefore sample selection bias exist. However, if IMR is not statistically significant, the model has no problem with sample selection bias (Heckman, 1979; 1980).

Empirical estimation. From the previous section, it was clear that estimating a treatment effect model involves a two-step and would provide consistent estimates in the farm income model. Therefore, the following empirical methods were estimated using maximum likelihood estimators. 
In the first stage, the probit model that defined access to credit is given as:

$$
\begin{aligned}
\text { Creditaccess }= & \beta_{0}+\beta_{1} \text { Gender }+\beta_{2} \text { Age }+\beta_{3} \text { Age square }+\beta_{4} \text { Education }+\beta_{5} \text { Household size }+\beta_{6} F B O \\
& +\beta_{7} \text { Extension }+\beta_{8} \text { Farm size }++e_{1}
\end{aligned}
$$

The substantive equation estimated at the second stage (OLS) can be expressed as:

LnFarm income $=\gamma_{0}+\gamma_{1}$ LnFarm size $+\gamma_{2}$ LnLabour $+\gamma_{3}$ LnWeedicides $+\gamma_{4}$ LnIn sec ticides $+\gamma_{5}$ Credit $+e_{2}$

Where credit access is defined as 1 if a farmer had received credit and 0 if a farmer had not; gender is 1 if a male and 0 if female; age is the total number of years from birth of a farmer and age square is the multiplication of age by itself; education is the total number of years a farmer had being in a formal school; household size is the total number of persons in a farmer's household that shares and pool resources together; Farmer-based organization (FBO) is 1 if a farmer belonged to an FBO and 0 if a farmer does not; extension services if 1 if a farmer had received extension services for the past 12 months and 0 if not; and farm size is the total number of acres a farmer had cultivated. Also, farm income is the total income in Ghana Cedis $(\mathrm{GH} \phi)$ from the total number of crops cultivated by a farmer; labour is the total number of persons who worked as labour on the farm; weedicides is the total number of liters of weedicides used by a farmer; and insecticides is the total number of liters of the chemical used by a farmer. All data was taken for the 2014 cropping season and on 5 major crops (rice, maize, millet, groundnut and cowpea) grown in the district.

\section{RESEARCH FINDINGS}

Descriptive statistics of variables. Table 1 shows the mean distribution of the continuous variables included in the model. From the table, the youngest farmer was 17 while the oldest was 83 years old; with a mean value of 44 years. This is far above the national mean age of 24 and the Upper East regional mean age of 25. On the average, there are 10 members in a farmer's household. Considering the high mean age value, these household members could be a source of labour to the farmers. On education, there are some farmers who had no formal education while others had up to tertiary education.

Table 1 - Descriptive statistics of farmers

\begin{tabular}{lllll}
\hline Variable & Min & Max & Mean & Std. Dev. \\
\hline Age & 17 & 83 & 43.8 & 16.70 \\
Household size & 3 & 35 & 9.8 & 5.85 \\
Education & 0 & 16 & 1.7 & 3.71 \\
Farm size & 0.4 & 11.2 & 2.12 & 1.70 \\
Farm income & 78 & 1,600 & 287.52 & 270.81 \\
\hline
\end{tabular}

Source: Author's computation.

Averagely, a farmer had 1.7 years of formal education which indicates that the level of education is generally low among the farmers. A farmer has cultivated 2.12 hectares of land during the 2014 cropping season. Farm income ranged from $\mathrm{GH} \phi 78$ (\$20.52) to $\mathrm{GH} \phi 1,600$ (\$421.05) with an average income of $\mathrm{GH} \phi 287.52$ (\$75.66) per cropping season.

Factors influencing credit access among crop farmers. From the empirical estimation of the treatment effect models, a number of factors have been found having a significant influence on access to credit. As indicated in table 2, gender, age, age squared, education, FBO membership, farm size and access to extension services significantly influenced access to credit. The estimated Wald chi-square value was significant, indicating the appropriateness of the models fitted. Gender was found having a negative effect on credit access, meaning the female farmers had a higher chance of accessing credit or had less credit constraint than their male counterparts. This is quite ironical since one would have 
expected the female farmers to be credit risk averse than the males. However, with recent gender liberation and women commitment and ownership of farms, this is admissible. In most rural agricultural communities, production resources are held in custody by the males and the females can only have access to such production resources if their requests are granted by the male owners. This limits the availability of resources to the female farmers and perhaps has resorted to seeking credit for production.

Age and age squared variables were both significant but varying signs; while the former was positive, the latter was negative. Thus, older farmers have a greater probability of accessing credit at current production, but with projections, the younger farmers would also have a lesser credit constraint. A special case for credit access is the fact that these older farmers have higher resource ownership (for instance, land) than the younger ones, and therefore tend to produce better collateral to the credit providers. With time, when the benefits of encouraging youths into agriculture begin to manifest (from policy to practice), then the youths would also tend to have a better chance to accessing these services than the elderly. A similar finding was found by Dong et al., (2010) where they argued that younger farmers may be unable to clout personal comparative advantage for farm work under credit constraint.

Expectedly, farmers with higher years of formal education had a higher probability of accessing credit than those without or little formal education. This is because the educated farmers tend to understand credit conditions than the illiterate or tends to be at the forefront in times of credit programmes introduced into these communities. In order words, agricultural credit providers turn to rely on the educated farmers who are usually the elites in disseminating the service information to the farmers. From Mwambi et al., (2013), it was clear that conventional economic theory reckoned the vital role of education in financial markets since it improves people's understanding of information and taking worthwhile economic decisions.

In recent times, FBO membership is one of the criteria used by credit service providers or collateral used by farmers to access credit. FBO members usually provide resources, technical and production supports to each other and therefore able to help themselves obtain financial assistance from the financial markets. Therefore, it is logical that farmers belonging to an FBO would have a greater chance to access agricultural credit, hence the positive marginal effect of $\mathrm{FBO}$.

Access to extension service had a positive effect on access to credit. Thus, farmers who had had contact(s) with extension officers had a greater chance of accessing credit than farmers who had no contact with extension officers. This demonstrates the importance of extension service in agriculture, especially, making production resource available and easily accessible to the farmers. In recent times, extension services expanded from providing technical advice to linking the farmers to input and credit sources. The aim is to enhance the adoption of technical advice provided by the extension officers.

Table 2 - Determinants of Access to Credit

\begin{tabular}{|l|ll|}
\hline \multirow{2}{*}{ Variable } & \multicolumn{2}{|l|}{ Selection Equation (Access to credit) } \\
\cline { 2 - 3 } & Marginal effects & Standard Error \\
\hline Gender & $-0.701^{*}$ & 0.397 \\
Age & $0.255^{* * *}$ & 0.087 \\
Age square & $-0.003^{* * *}$ & 0.001 \\
Education & $0.103^{* *}$ & 0.052 \\
Household size & 0.045 & 0.031 \\
FBO & $0.896^{* * *}$ & 0.313 \\
Farm size & $0.152^{* *}$ & 0.062 \\
Extension & $0.140^{* * *}$ & 0.033 \\
Constant & 6.314 & 0.271 \\
\hline Wald chi square & $33.740^{* * *}$ & \\
\hline
\end{tabular}

***, ${ }^{* *}$ and * indicates significance at $1 \%, 5 \%$ and $10 \%$ respectively.

Source: Author's computation 
The size of farm cultivated by a farmer also determined farmers' access to credit. From the result, farmers with larger farms had a higher probability of accessing credit than those with smaller farms. This is because the larger farm owners require more resources such as labour, fertilizer and other agrochemicals for crop production. On the flip side also, credit providers would always want to provide credit to farmers with larger farms as the default rates among these farmers are expected to be lower. In order words, the larger farm owners moved beyond subsistence farming to farming as a business, hence borrowed to finance its production. However, the implication of this finding is that even among the smallholder crop farmers, the smaller farm size holders are continually marginalized and may continue to be vulnerable to subsistence farming.

Effect of Agricultural Credit on farm income. The second stage (OLS model) of the Heckman examine the influence of access to agricultural credit on farm income. The IMR for the model is significant and positive, which implies that the error term of the selection equation (the probit model) and that of the outcome equation (OLS model) are positively correlated. This suggests that the unobserved factors that increase access to agricultural credit are likely to be associated with higher farm income. The results also means that sample selection is a problem in the data set, hence Heckman model is appropriate. The study estimated a positive effect of access to agricultural credit on the farm income. This means that farmers who accessed agricultural credit had higher farm income than those without. This is an important finding since farmers would be able to retrench their credits. This finding also justifies support for crop farmers in the district since they may be able to maximize their farm incomes. Empirically, Shah et al., (2008) also estimated a positive effect of credit on crop yield and income of the borrowers over the non-borrowers. Dong et al., (2010) concluded from their study that both productivity and household income can be improved by $31.6 \%$ and $23.2 \%$ respectively if credit constraints are eliminated. Similarly, Asres et al., (2014) found that efficiency can be improved through credit provision. Other factors that had a significant influence on farm income were labour and farm size; both with positive elasticities. The implication is that as these variables increase, farm incomes would also increase.

Table 3 - Effects of access to Agricultural credit on Farm income

\begin{tabular}{|c|c|c|}
\hline \multirow{2}{*}{ Variable } & \multicolumn{2}{|c|}{ Outcome Equation (Farm Income) } \\
\hline & Coefficient & Standard Error \\
\hline Labour & $0.496^{* * *}$ & 0.130 \\
\hline Farm size & $0.180^{*}$ & 0.101 \\
\hline Weedicides & -0.126 & 0.143 \\
\hline Insecticides & 0.004 & 0.151 \\
\hline Selection variable (Agricultural credit) & $0.959^{* *}$ & 0.420 \\
\hline Constant & 6.598 & 0.18 \\
\hline Lambda & $0.556^{* *}$ & 0.278 \\
\hline
\end{tabular}

${ }^{* * *},{ }^{* *}$ and ${ }^{*}$ indicates significance at $1 \%, 5 \%$ and $10 \%$ respectively.

Source: Author's computations.

For instance, a $100 \%$ increase in labour and farm size would respectively result to about $50 \%$ and $18 \%$ increase in farm income. In crop farming, these two variables are unavoidable resources that must be provided.

\section{CONCLUSIONS AND RECOMMENDATIONS}

Farm income is an important component of rural life. Almost all persons in the rural farm communities are engaged solely in agriculture and obtain all the needs from agricultural activities. Therefore, measures that would help improve the income of the farmers are in the right direction. From this study, access to agricultural credit which is vital for improving farmers' livelihood measures was found to have a positive impact on farm income improvement. Therefore, improving access to agricultural credit could be a potential source of poverty reduction among farm households. These are important findings that justified support for the smallholder farmers. Considering the importance of crop farming in rural communities, the study concluded that agricultural credit provisions could become an 
important step to improving welfare status among farmers since their farm incomes would be improved. However, efforts must be taken to ensure that smaller farm holders among the smallholder farmers are given much attention in credit disbursement. Also, the following policy recommendations should be considered:

I. Educational programmes should be intensified in the district. Also, educated people who lacked capital for crop production should be encouraged to go into farming since they have a greater probability of accessing credit. Similarly, female farmers (they have a greater chance of accessing credit) are encouraged into farming since these services could help address the lack of production resources among female farmers in rural communities.

II. FBO should be promoted in the district while credit providers should intensify support to these farmers. This would serve as a source of motivation to other farmers to join FBOs.

III. Farmers are encouraged to expand their farmlands in order to increase their chance of accessing agricultural credits and also, maximize their farm incomes.

IV. Credit providers should extend support to more farmers in the district. However, precautionary measures such as education and monitoring should be taken to ensure that farmers use the credits received for the right purpose for higher incomes.

$V$. One of the limitations of this study is that it focused mainly on econometric estimation, hence, the inability to describe the conditions, collateral requirements and challenges to accessing credit service. Therefore, further studies that would address these issues may provide additional information relevant for policy makers.

\section{REFERENCES}

1. Asres, E., Makoto N., Kumi Y., Akira I., Arega D. A. (2014). The effect of agricultural extension service on the technical efficiency of teff (eragrostistef) producers in Ethiopia. American Journal of Applied Sciences, 11 (2), 223-239.

2. Dong F., Lu, J., Featherstone, A. M. (2010). Effects of Credit Constraints on Productivity and Rural Household Income in China. Working Paper 10-WP 516.

3. FAO, (2015). The state of food and agriculture. Social protection and agriculture: breaking the cycle of rural poverty. FAO of the United Nations, Rome.

4. Greene, W.H. (2003). Econometric Analysis. Pearson, New York, p 1026.

5. Greene, W. H. (2008). Econometric Analysis (6th Edition). New Jersey: Prentice-Hall, Upper Saddle River.

6. GSS (2012). Ghana Statistical Service, 2010 population and housing census summary report of final results May, 2012.

7. GSS (2014). Ghana Living Standards Survey round 6 (GLSS6).Poverty profile in Ghana (2005-2013). Ghana Statistical Service, August, 2014.

8. Heckman, J.J. (1979). Sample Selection Bias as a Specification Error. Econometrica, 47, 153-161.

9. Heckman, J.J. (1980) Sample selection bias as a specification error. In: female labour supply: theory and estimations, ed. J.P. Smith. Princeton University Press, Princeton, pp 206-249.

10. Meyer, R. (2007). Microfinance services for agriculture: opportunities and challenges. Paper for the international conference What Can Microfinance Contribute to Agriculture in Developing Countries? Paris, 4-6 December 2007, 12.

11. Mwambi M., Oduol J., Mshenga P., Saidi M. (2013). Does Contract Farming Improve Smallholder Farmers Income? The Case of Avocado Farming in Kenya.Invited paper presented at the 4th International Conference of the African Association of Agricultural Economists, September 22-25, 2013, Hammamet, Tunisia.

12. Quaye, W. (2008). Food Security Situation in Northern Ghana, Coping Strategies and Related Constraints. African Journal of Agricultural Research, 3(5), 334-342.

13. Shah M. K., Khan H., Jehanzeb, Khan Z (2008). Impact of agricultural credit on farm productivity and income of farmers in mountainous agriculture in northern Pakistan: $A$ case study of selected villages in district Chitral. Sarhad Journal of.Agriculture, 24(4), 713-718. 